\title{
Is current forest landscape research approaches providing the right insights? Observations from Indian context
}

\author{
Rama Chandra P. Prasad, Krishnan S. Rajan
}

Laboratory for Spatial Informatics, International Institute of Information Technology, Gachibowli, Hyderabad - 500032, India, e-mail: rcprasad@iiit.ac.in

\begin{abstract}
One of the major challenges in the current scenario for ecological conservation is to quantify the forest landscape in its spatio-temporal domain and understand further implications of those. While the detailed study of the forest ecosystems may provide insights into biodiversity, carrying capacity and productive nature, most of the studies are restricted to single time/event inventory and focused on assessment of tree diversity patterns. Through the adoption of geospatial technologies like remote sensing and Geographical Information System (GIS), though forest monitoring has been possible, the linkages to the biodiversity distribution and its patterns are still at an empirical level, thus supporting broad measures of protection and preservation without accounting for the local/regional variability.

Towards this the paper discusses the lacuna in the current landscape research approaches in Indian scenario. Presents a framework to analyze the landscape structure at the, micro, meso and macro levels. Emphasize the need for the collection of spatio-temporal field data to analyze the change in biodiversity and their linked entities. The paper suggests the need for development of long term ecological area networks to understand the ecological processes, making the data open and improve collaborations among the organizations working in the similar domain to enhance the impact of the research works.
\end{abstract}

Keywords: Biodiversity, carbon, climate change, holistic approach, open source.

\section{Introduction}

Forest landscape, one of the major biome systems on the earth, provides vital ecosystem services required for the sustainability and survivability of the human beings. Services not only include benefits with their valuable forest products, but also indirect contributions in the global carbon cycle, watershed protection etc, (Verma 2001). However, these ecosystems in turn are subjected to various direct and indirect anthropogenic pressures and threats, which question their existence in the near future (Richard 1994; Burke \& Franklin 2003; Prasad et al 2011). Keeping in view of the alarming rate at which these resources are degraded and depleted, researchers globally diverted their attention in executing conservation and protection measurements of these resources (Butler \& Laurance 2010; Laurance \& Bierregaard 1997).
Towards this the first step is to preserve the existing resources by a way of tagging them with ecological significance in terms of their biodiversity focusing on species richness, endemism etc., (Myers et al. 2000). The second step is to monitor those resources at the regular interval of time as well as check and manage the changes if any including degradation process. The third step is to identify the role of various socioeconomic factors that are threatening the system currently and develop mechanisms to manage and conserve them suitably. But, in the present scenario, it appears that the research in addressing landscape issues is not fully understood in a systematic way and there exists extrication between the links of research. In this context, in the current paper, we tried to bring out some kinds of concerns that should be addressed to make the landscape research more holistic way, for better protection and sustainable implications. 
In the view of current direction of research in India we categorize the content into three themes - field surveys-analysis, use of geospatial tools and socioeconomic drivers, to discuss and highlight the pros and cons of the current approaches. The discussion on ecological, vegetation and species succession models are out of the scope of this paper. Later in the paper, we come up with a simple framework of integrating the three methods that suit for forest landscape research design. Though the concepts discussed are generic globally, but our focus is more within the Indian context and more specific to phyto studies. Yet, the notions can be implied to any region that has similar context.

\section{Field inventory related issues}

Comparison of results: To aim at the first step of the above discussion, the researchers started exploring different forest biomes to quantify the forest landscape system for their phyto-diversity. Simultaneously, they compared the values obtained in their study area (forest types) with reference to other studies done in the forest types elsewhere globally. The majority of the research papers generally focuses on this direction of assessment. This is something needs to be addressed strongly from the ecological point of view. The climatic, edaphic and topographical conditions vary across the regions, though broadly appear similar for comparisons (for example evergreen/wet or deciduous). The local conditions are still important to consider when we compare species richness, diversity, stems per hectare or any other parameter of interest. Comparison of similar forest types globally may be appropriate to a certain extent (even though local environmental gradients for same forest type vary), but it may not be apt to contrast dissimilar forest types. Comparisons between evergreen systems may be fitting, but among evergreen $v s$ deciduous, dry deciduous $v s$ moist deciduous or any other forest types may under or overestimate the diversity patterns of forest systems of a region. For example, a researcher working on dry deciduous forest compares diversity parameters with respect to evergreen or moist deciduous may not be apposite (ex. Panda et al. 2013; Pitchairamu et al. 2008). Moreover, when researchers are quantifying the phyto-diversity of the region, the majority focus on tree diversity ignoring other strata like shrubs, herbs, climbers, ferns etc. though few studies take into account of all the strata and in some cases exclusively on lower strata, but this kind is rare (ex. Rasingam \& Parthasarathy 2009).

The majority of the studies focus on random inventories to capture the diversity patterns (Gupta \& Prasad 2014; Prasad et al 2007; Gordon \& Newton 2006). Interestingly surveys for this study are mostly done in the accessible area may be on flat terrains and in a few instances along

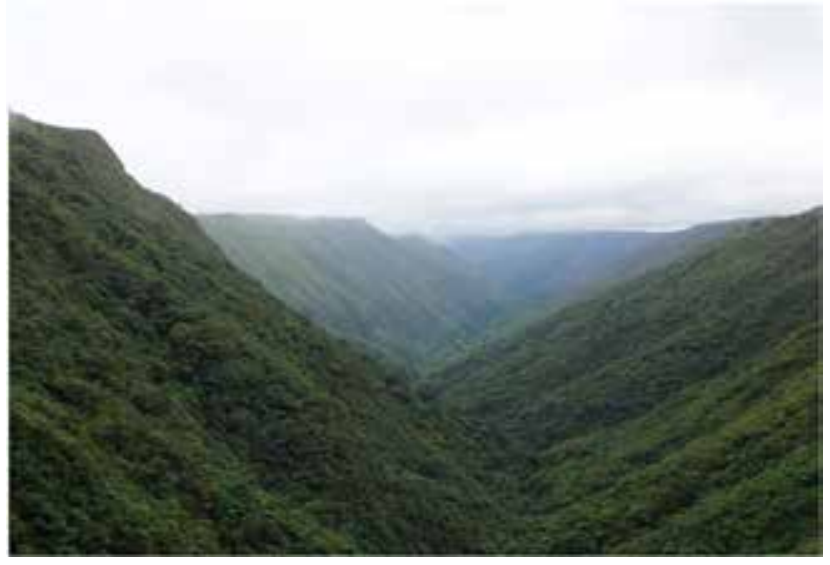

Figure 1. A dense Vegetation Structure in the Meghalaya State of India

the altitudinal gradients, further extrapolating the diversity values for the entire area. But there are certain areas which were not covered during the inventory process due to their inaccessibility that may encompass a different variety of species distribution. How to accomplish this kind of data? For example, the Figure1 shows the vegetation structure in the Meghalaya State of India, but how to account species richness and diversity status of these vegetation entities?

Type of plots for field inventory: Field inventory generally involves sampling of defined size and shape of sample plots for the collection of phyto related information. It can be random/ contiguous sampling or transect belt along a gradient. The size of the plot varies across the vegetation types based on the species-area curve; also the shape (circular or square) and normally results are generalized for comparison at per hectare level. The researchers should follow a unique method of distribution of sample plots, so that they can capture the heterogeneity within the area. But the current approach is a bit reverse, plots are chosen based upon their accessibility and feasibility on the ground. This obviously will not give a true picture of the study area about its diversity measurements.

Calculation of species diversity: Another major point to consider is the calculation of diversity pattern. A number of statistical indices are proposed to analyze the species diversity. However each has its own limitation and users should choose an index that is appropriate to their method of field data collection. The research groups are generally biased or fantasized to use a number of indices that are available in the literature or a software package, without having a significant understanding about the performance of those indices. One interesting point with reference to Shannon-Wiener index (1963) is a consideration of the log value. 
$H=-\sum_{i=1}^{S} p_{i} \ln \left(p_{i}\right) \quad$ Or $\quad H=-\sum_{i=1}^{S}(n i / N) \ln (n i / N)$

$H=$ Species Diversity Index, $S$ - the number of species in the sample; $p i-$ relative abundance of $i$ th species $=n i / N ; N$ - total number of individuals of all the species, $n i$ - number of individuals of $i$ th species, ln-natural logarithm $\left(\log _{\mathrm{e}}\right)$.

Some researchers use $\log _{2}$ or $\log _{10}$ instead natural logarithm (ln) and comparing such kind of results will yield different scenarios about diversity. Natural logarithm use $\log$ base $e$ and use of the $\log _{\mathrm{e}}$, during diversity calculation will give low and high values compared to $\log _{2}$ and $\log _{10}$ respectively for the same region / data. Hence it is necessary to emphasize the log value chosen while calculating the index. This perhaps helps the researchers to compare diversity values of their region with other regions (of similar type) to know its ecological status.

Further in their paper on Andaman Islands, Padalia et al. (2004), described index as

$H=-\sum\left[(n i / N) \log _{2}(n i / N)\right](\log$ implies to log base 10)

What does this mean? It is not clear whether they have used the $\log$ (which represent simple $\log _{10}$ ) or $\log _{2}$. This kind of implications creates confusion for the readers. Also, in their study (Padalaia et al 2014), they reported diversity value for different forest types of Andaman ranging from 1.07-2.05. These values indicate that they might have used $\log _{10}$ instead $\log _{2}$ In addition, they compared their diversity values with the study of Singh et al (1981, for Silent Valley, who used $\log _{2}$ in calculating diversity- 3.52-4.15.) and commented that the diversity of the Andaman Islands is low compared to Silent valley. Contradicting their study, Prasad et al (2007), in their diversity analysis (using $\log _{2}$ ) of major forest types of North Andaman Islands reported Shannon index values ranging from 5.7-6.0. These values are far higher than what Padalia et al (2004) reported for Andaman Islands, if we assume that they have used $\log _{2}$ for diversity calculation. Interestingly Shruthakeerthiraja and Kumar (2012), in their study on the Western Ghats, India, compared their diversity values (claimed to use natural logarithms in Shannon index) with Padalia et al (2004) and reported a high diversity (2.38) in their study area in comparison to the Andaman Islands. In general, Andaman Islands encompass high species diversity and endemism (refer Anonymous 2003, Roy et al 2005, Prasad et al 2007). Studies like Padalia et al (2004) may portray a false picture about the real species richness of area and ranks them lower in comparison to other areas.
Similarly, Roy et al (1993) in their study on middle Andaman Islands showed diversity values in the range of 0.6 to 1.4 which is low with reference to the study of Gupta and Prasad (2014) who recorded highest diversity of 3.8 for the same region. However, both the studies have not mentioned the log value used for calculation of Shannon Index. It is obvious from above that for the same region diversity values vary depending on the use of $\log$ base values.

Identification of species: Next comes, the identification of species, which is very much crucial and important. Usually researchers identify a tree based on their expertise or taxonomical knowledge and in some cases with their local names later connecting by scientific names, or taking the specimens tagged with vouchers and categorizing using either flora or specimens present in the regional herbarium. It may not be difficult to make out the common species, but significant care must be taken in identifying a new species or sometimes even common one too. The study of Padalia et al (2004) reported a species name Dipeterocarpus grandis, but there are no records globally with reference to the Dipterocarpaceae family having such kind of species (Prasad 2011). Does it really a new species found only in Andaman? Then in any case it should be highlighted as a new discovery.

Also the detailed study on biodiversity characterization of Andaman and Nicobar Islands using remote sensing and GIS (Anonymous 2003) reported the presence of a species Hopea Odorata of Dipterocarpaceae from Nicobar Islands. However, it is to note that the family Dipterocarpaceae is restricted only to the Andaman Islands (Singh et al. 2002; Mathew et al. 2010; Prasad 2011), and reporting this species in Nicobar Islands is really an example of island biogeography and species migration. But how far the identification is authentic? In both of the above studies senior expert taxonomist was involved and the research work is published in a reputed journal. This kind information may be referred by the other researchers working in the same region or other and the content (maybe an error?) is propagated. If the data are true the research is in the correct direction, but if not, then?

In some instances, the same species is described with a different name, making it as a new species. Vasudeva Rao (2004) quoted examples supporting this statement for Andaman Islands with reference to Dipterocarpus turbinatus var. andamanica and Dipterocarpus andamanicus. The debate is whether they are two different species or same with different names.

Long-term Ecological Research Plots: To better understand the ecological processes like succession, dominance, climatic effect, species turnover, nutrient cycle and biodiversity changes, the concept of long term ecological plots came into existence. Within the Indian scenario, this kind of initiation started in the Mudumalai forest by Sukumar 


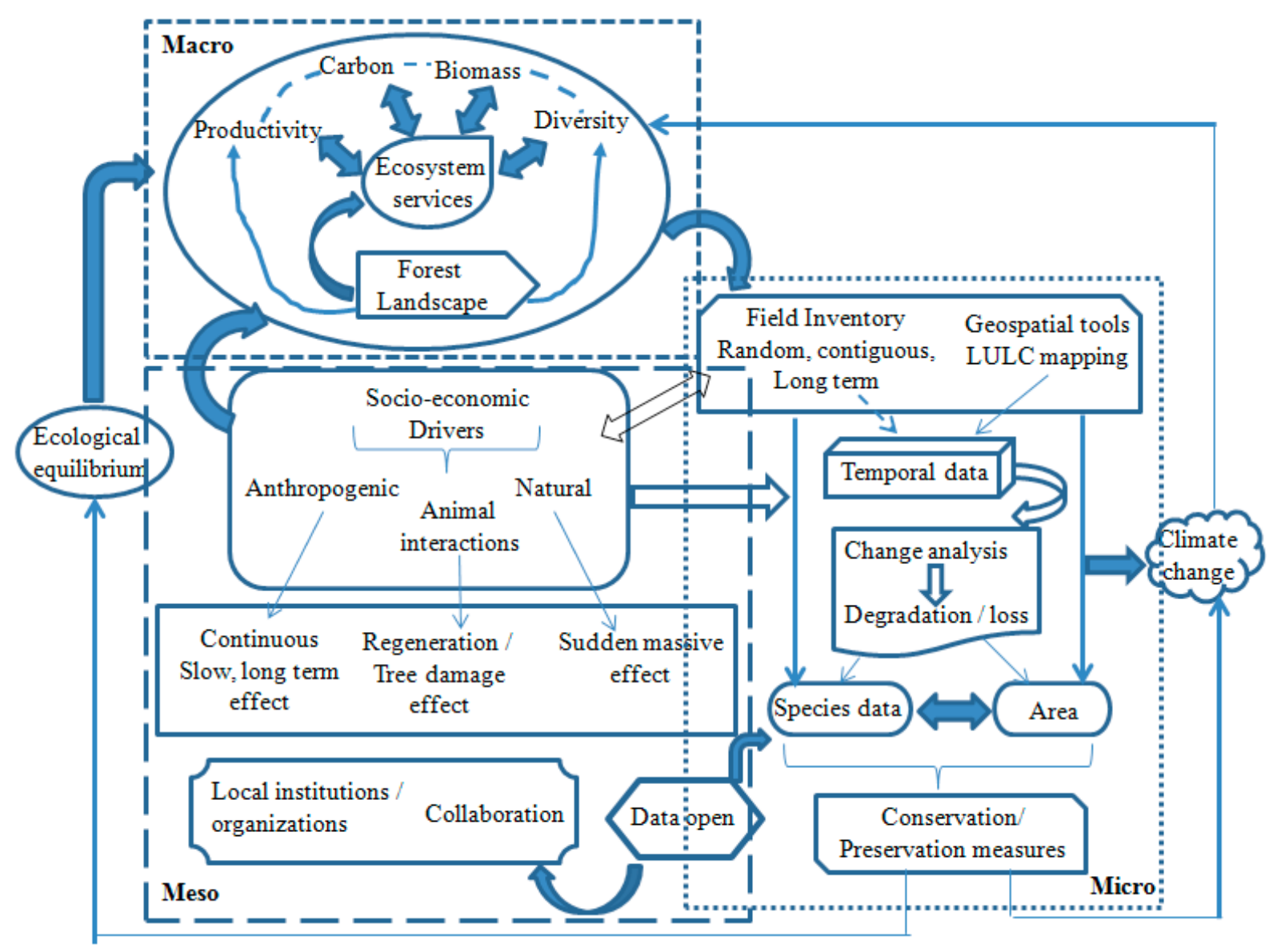

Figure 2. Proposed framework for assessing the various interactions within the forest landscape

et al. (1992) by surveying an area of 50 hectares (ha) plot covering deciduous forest. This is in fact one of the major contribution in the field of ecology to assess and analyze the impact of natural and anthropogenic interactions in relation to forest ecosystem services. However there is no such kind of similar research plot in other forest systems within India. The reason, perhaps may be lack of funding source to support a long term research coupled with an organization that can take up such kind of task in a long way.

Few studies emerged in the similar pathway, but are restricted to single time inventory and lower size plot. For example 30 ha plot by Ayyapan and Parthasarathy (1999), 3 ha plot by Prasad et al (2009a) and lowest of 1 ha plot (Rajkumar \& Parthasarathy 2008). These kinds of inventories are able to capture the species behavior patters in contiguous plots along with those species that prefer a patchy environment or restricted distribution.

Linking diversity loss with loss of other parameters: Most of the research within the Indian scenario focused on analyzing diversity patterns in varied forest types and across the gradients may be altitude, aspect, slope etc. But, should also consider another side of diversity relations if, one's aim is to quantify the forest landscape with its intrinsic characteristics. A number of projects done to characterize the biodiversity of different regions of India are finally ended up with a report on forest fragmentation and tree diversity trends. However the research should also focus on bringing out ecological linkages between diversity and other parameters like biomass, carbon, etc (Fig. 2).

Initiation of studies assessing biomass and carbon in the forests of India has taken off, but most of them are on either at the State level or on major forest types of the country. Few researchers attempted to focus on analyzing carbon of forest types within the state along topographical gradients. It seems the research is going on parallel lines and at this stage there is a need to synchronize both the themes to derive and depict the overall eco-significance of the forested landscape. The research with respect to linking diversity, biomass and carbon loss is still on rudimentary stage and new avenues should focus in this direction to come up with possible inter-linkage dependency among forest landscape parameters (Fig. 2).

Further in a more advanced method of analysis, the concept of green accounting should be integrated such that 
loss of biodiversity can not only be figured as number decrease but also quantify in terms of monetary loss. The research probably should bring out the connection of biodiversity loss with loss of ecosystem services, and to achieve this temporal field data is quite handy along with the rate at which resources are exploited and depleted.

Lack of temporal field inventory data: One drawback with current research inventory is the inclusion of temporal data analysis (Fig. 2). Given a wide range of studies carried out so far in the country along with the publication of data in the form of literature, no attempt was carried out to re-survey the same location. This is particularly important if the focus is to enumerate the loss of species in the given region during the course of time, due to various interactions. Lacuna with this kind of approach is the availability of historical database in the public domain. Even if exists, no researcher is interested, either to explore the same area for temporal analysis or not aware as well as not willing to use such data for species change analysis. Proper conservative measures can be implemented in a more systematic way, if one knows what kind of species are lost and what type of habitat they are preferred for their sustainability. But most inventory studies end up with general conclusion, linking with deforestation and human interactions.

Coordination and collaboration among organizations: There should be proper coordination and collaborative initiative among the organization when they are working in similar region so that a better current and past data can be compiled for improved implications / suggestions of conservation. Nevertheless one significant contribution of the current approach of field inventory is obtaining detailed floristic entities existing in the given area. At the same time emphasizing on a number of rare, threatened, endemic species that enhance the ecological significance of such ecosystems to be declared as the so called 'Hot spots' (Myers 1990).

In a way it appears that the research is based on the concept of 'something is better than nothing' and surely provides baseline data about the floristic composition, uniqueness and threats that they are facing in the present scenario. Yet it is suggested to shift the paradigm of research in more sophisticated, technical, economical way by taking into account of various parameters and understanding their linkages, dependency and risk of instability of ecological equilibrium.

\section{Geospatial tools in enhancing landscape research}

Beside the traditional way of ecological and traditional survey methods, the use of geospatial tools like remote sensing and GIS has gained much significance in the assessment of forest landscape diversity (Menon \& Bawa
1997; Prasad et al 2009b). The spatial, spectral and temporal characteristics of satellite data are helpful in deriving thematic output with reference to land use land cover (LULC) patterns of a region. Further the use of moderate to high spatial resolution multispectral satellite data aided in deriving forest types of regions. Also the availability of the temporal satellite data made it possible to quantify the rate of changes these landscapes are undergoing in view of rapid human interactions (Prasad et al 2009c). The thematic map derived by analyzing current satellite data depicts the current forest status and used as baseline data for random distribution of sample plots for field inventory. However, temporal spatial changes can be assessed by remote sensing, but unable to get information about the past biodiversity data. To anticipate this, some researchers try to relate the extent of loss of forest to loss of biodiversity, without any quantification about the exact number and type of species lost.

In a general sense, from the moderate resolution satellite data forest types can be mapped but not up to the species level. Researchers made an attempt to derive species level information by making use of high spatial resolution satellite data, which is quite expensive. The use of hyperspectral remote sensing is economical but, their availability is infrequent. Also the technique of deriving information from these datasets using different algorithms is not at mature.

The scientist communities are more adapted to the use of moderate and coarse satellite data for mapping either at region or at unit level and mostly mapping the LULC and deriving parameters with respect to their biomass, productivity, species richness, diversity etc. There is need to focus more on these lines of research at the same time incorporating other geospatial data like microwave, thermal, LIDAR (Light Detecting and Ranging) for better management of landscape structure. There is a need for capacity building programmes with respect to use of these advanced geospatial technologies.

\section{Socio-economic drivers of landscape changes}

The research is accomplished to be a full when there is an integration of geospatial data, field inventory data with that of socioeconomic factors. This kind of analysis will provide a holistic approach for the assessment of the landscape diversity. Imagine a scenario when there are no socioeconomic factors prevail in a system. The system remains more or less always in its equilibrium unless there are major natural catastrophes. However, since the existence of mankind landscapes are under various levels of pressure, thus metamorphosed during the course of time. In the current scenario, major changes in the landscape structure are 
due to various socio-economic drivers (human-origin) and in some case animal interactions too, along with sudden natural disasters. So when quantifying forest landscape it is necessary to view its diversity and richness in relation to its associated LULC features along with the pressure of interactions.

As an example to elucidate this statement, a conceptual framework was proposed by Prasad et al (2010). This frame work mainly focuses on the various factors that have contributed to the forest changes in North Andaman Islands. The elements of the framework include legal and illegal logging practices, the impact of government policies, implementation of future plans that may impact forests, animal interactions - role of animals in the loss of forest, loss in biodiversity incur due to scientific floristic inventories, along with a natural disaster like a tsunami. The study showed inter linkage among different factors that might have ultimately changed not only forest area but in long way transformed forest types that these islands originally should possess. Thus the role of climate was also incorporated as one of the drivers for forest changes.

\section{Frame work for assessing landscape}

The systematic way of landscape assessment should include an integration of research at macro, meso and micro scales. Macro-scale assessment involves estimations of landscape parameters and identifying interdependencies among them. For example, bringing out significant correlation between carbon-biomass/diversity-carbon/ carbon-ecological productivity. Meso-scale mainly focuses on various socioeconomic factors contributed towards modification of landscape entities and discusses how the absence of one entity effects or impacts another and finally the climate. The micro-scale study includes analyzing the landscape changes and quantifying the area in terms of biodiversity or highlighting its biological richness using geospatial techniques and field inventory studies. Nevertheless, for better understanding landscapes intrinsic phenomena and holistic structure, studies should focus on taking into consideration of all the three scale scenarios.

Also, the user perception should be broad enough to look at the system as a whole rather than as the smallest unit. For example, when a LULC thematic map derived from geospatial data, is given to forestry practitioner, his focus will be more towards forest types and their changes. An urban planner view will be on urbanization and settlement expansion and agglomerations. An overall observation, taking LULC as a major component of the landscape may provide more insights and further linking socioeconomic data in conjunction with field inventory data gives better understanding of ecosystem for implementation of safeguarding measurements.
In the light of above context this paper proposes a generalized integrated framework for landscape research, encompassing the various thematic components across the multiple scales of interaction (as shown in Figure 2). The model highlights the interlinking relation between the ecological themes - diversity, carbon, biomass and productivity. This is one of the least understood phenomena, though it exists as an inherent property of landscape structure. The model also proposes to have a mutual coordination and collaboration among different regional units to explore the landscape in its spatio-temporal domain for best practices.

It also emphasizes the need to have temporal data and make the collected data 'open' for the public, so that more productive analysis related to species change and loss can be enumerated. A few recent developments in this line are: the Western Ghats portal, which is made open (http://thewesternghats.indiabiodiversity.org), where users can download as well as add data with reference to a particular species. Another to quote is Western Ghats Spatial Database Infrastructure (WGSDI), a fully developed SDI (http://lsi. iiit.ac.in/WGSDI1.0/) that allows user to visualize data along with other LULC maps and Survey of India toposheets. It provides tools for data upload/addition through web interface and android based mobile devices. It also renders data through web services, which can be discovered by other geoportal or SDI for accessing this data seamlessly over the internet. In a way this kind of mechanism builds up good quality species data over a period of time. Such kind of openness related to data should be made mandatory, especially when support / funds are from government organizations.

Overall one point of concern is though there is ongoing landscape research by various organizations, universities, the lack of building a concerted synoptic view with which these can be brought together and help re-define the research focus from time to time is lacking or limited. It is suggested to have a database system to share the data collected among the units for better collaborative research. Since it is not possible to survey the entire landscape keeping in view of time and other factors, the best way is to assign certain areas (forest landscape) to concerned regional institutions and organizations, so that the researchers over a period perform their research in the same area may be measuring the same parameters or different. This kind of work in the course of time fills the gap of temporal field data for a given location and surveys at frequent intervals of time make it possible to assess the changing diversity patterns.

The emerging fields of ecology and environmental sciences in academia as well as in research organizations provides better technical human resources to carry out such kind of regular collection and analysis of field data. There should be interdisciplinary collaboration among the units, i.e. one group providing taxonomic surveys, and the other 
with geospatial technology in conjunction with socioeconomic aspects. This kind of co-ordination along with the formula of making the collected data open will enhance research potentiality and benefits in the assessment of landscape parameters.

Since the advancement of geospatial technology in India, several studies were carried out in different forest ecosystems to analyze their spatio-temporal changes along with biodiversity components. The work is still going on. But are there any evidences of using these results by any organizations/institutions either government or private? Are there any studies showing the positive results derived by using the implication suggested for conservation in the studies carried out for a specific region? The majority of the thesis, field studies, and research work is restricted as department reports or published as research papers either in conference or journals/book. How far these studies are really utilized for the betterment of the landscape protection and conservation is open for debate.

\section{Conclusions}

The integrated approach of using different techniques and methods benefits the researchers to look into landscape structure at different angles and to present a more synoptic measurement by analyzing all the factors. This perhaps may prove to be the best way to decipher the intrinsic properties of landscape and its components in the light of current trends.

Towards this there is a need to formalize or materialize or in a broad sense revise the landscape research within the country using the proposed framework as a start point for developing it. It is acceptable to use/follow previous method for the landscape studies, but during the course of time they should be revised. A revision in a systematic way by considering all the aspects discussed in the paper, can go a long way towards the holistic approach of landscape conservation or preservation.

\section{References}

Anonymous, 2003, Biodiversity characterization at Landscape Level in Andaman and Nicobar Islands using Satellite Remote Sensing and Geographical Information System, Indian Institute of Remote Sensing, Dehradun.

(http://www.teriuniversity.ac.in/mct/pdf/Wildlife_Module/ Island_Biodiversity/BIODIV 1.PDF)

Ayyappan N. \& Parthasarathy N., 1999, Biodiversity inventory of trees in a large-scale permanent plot of tropical evergreen forest at Varagalaiar, Anamalaias, Western Ghats, India. Biodiversity and Conservation 8: $1533-1554$.
Burke C. A. \& Franklin T. M., 2003, Policy News: Threats to Natural Resources Management, Wildlife Society Bulletin 31(4): 1238-1239.

Butler R. \& Laurance W., 2008, New strategies for conserving tropical forests, Trends in Ecology and Evolution 23(9): 469-472.

Gordon J. E. \& Newton A. C., 2006, Efficient floristic inventory for the assessment of tropical tree diversity: A comparative test of four alternative approaches, Forest Ecology and Management 6(237): 564-573.

Gupta S. \& Prasad R. C. P., 2014, Analysis of tree diversity patterns in the tropical evergreen and moist deciduous forests of the Middle Andaman Islands, India, Journal of Biodiversity Management and Forestry 2:3 [doi:10.4172/2327-4417.1000114].

Laurance W. F. \& Bierregaard Jr. R. O., 1997, Tropical Forest Remnants: Ecology, Management and Conservation of Fragmented Communities, The University of Chicago Press, Chicago.

Mathew P. S., Radha R. K., Krishnan N. P. \& Seeni S., 2010, Phytogeography of the Andaman-Nicobar Islands with special reference to Hornstedtia fenzlii (Kurz) K. Schum, Current Science 98 (7): 905-907.

Menon, S. \& Bawa, K. S., 1997, Application of geographic systems, remote sensing and landscape ecology approach to biodiversity conservation in the Western Ghats, Current Science 73(2): 134-145.

Myers N., 1990, The biodiversity challenge: expanded hotspots analysis, Environmentalist 10(4): 243-256.

Myers N., Russell A., Mittermelert C., Mittermelert G., Gustavo A. B. \& da Fonseca J. K., 2000, Biodiversity hotspots for conservation priorities, Nature 24: 853858.

Padalia H., Chauhan N., Porwal M. C. \& Roy P.S., 2004, Phytosociological observations on tree species diversity of Andaman Islands, India, Current Science 87(6): 799-806.

Panda P. C., Mahapatra A. K., Acharya P. K. \& Debata A. K., 2013, Plant diversity in tropical deciduous forests of Eastern Ghats, India: A landscape level assessment, International Journal of Biodiversity, and Conservation 5(10): 625-639.

Pitchairamu C., Muthuchelian K. \& Siva N., 2008, Floristic inventory and quantitative vegetation analysis of tropical dry deciduous forest in Piranmalai Forest, Eastern Ghats, Tamil Nadu, India, Ethnobotanical Leaflets 12: 204-216.

Prasad R. C. P., 2011, Ecological analysis of Dipterocarpaceae of North Andaman forest, India, Journal of Plant Development 18:139-145.

Prasad R. C. P., Rajan K. S., Dutt C. B. S. \& Roy P. S., 2010, A conceptual framework to analyse the Land-use / land-cover changes and its impact on phytodiversity 
- A case study of North Andaman Islands, India, Biodiversity and Conservation 19(11): 3073-3087.

Prasad R. C. P., Reddy C. S., Vijaya Kumari P., Varalakshmi R. K., Raza S. H. \& Dutt C. B. S., 2009a, Vegetation structure and ecological characteristics of forest of North Andaman Islands, (India), Biological Letters 46(2): 105-121.

Prasad R. C. P., Rajan K. S. \& Asha Kumari J., 2011, Endangered forest ecosystem of Eastern Ghats - need for conservation of Kondapalli forest, IUP Journal of Life Sciences 5(4): 40-45.

Prasad R. C. P., Reddy C. S. \& Dutt C. B. S., 2007, Phyto-diversity assessment of tropical rainforest of North Andaman Islands, India, Research Journal of Forestry 1(1): 27-39.

Prasad R. C. P., Sringeswara A. N., Reddy C. S., Nidhi N., Rajan K. S., Giriraj A., Murthy M. S. R, Raza S. H. \& Dutt C. B. S., 2009b, Assessment of Forest Fragmentation and Species Diversity in North Andaman Islands (India) - A Geospatial Approach, International Journal of Ecology and Development 14: 33-46.

Prasad R. C. P., Reddy C. S., Rajan K. S., Raza S. H. \& Dutt C. B. S., 2009c, Assessment of Tsunami and Anthropogenic Impacts on the forest of the North Andaman Islands, India. International Journal of Remote Sensing 30 (5): 1235-1249.

Rasingam L. \& Parthasarathy N., 2009, Diversity of under storey plants in undisturbed and disturbed tropical lowland forests of Little Andaman Island, India, Biodiversity Conservation 18(4): 1045-1065.

Rajkumar M. \& Parthasarathy N., 2008, Tree Diversity and Structure of Andaman Giant Evergreen Forests, India, Taiwania 53(4): 356-368.

Richard M., 1994, Toward valuation of forest conservation benefits in developing countries, Environmental Conservation 21(4): 308-319.
Roy P. S., Singh S. \& Porwal M. C., 1993, Characterization of ecological parameters in tropical forest community - a remote sensing approach, Journal of Indian Society of Remote Sensing 21(3): 127-149.

Roy P. S, Padalia H., Chauhan N., Porwal M. C., Gupta S., Biswas S. \& Jagdale R., 2005, Validation of geospatial model for biodiversity characterization at landscape level-a study in Andaman and Nicobar Islands, India, Ecological Modeling 185(2-4): 349-369.

Shannon C. E. \& Wiener W., 1963, The Mathematical Theory of Communication, University of Illinois Press, Urbana, USA.

Singh, J. S., Singh, S. P., Saxena, A. K. \& Rawat, Y. S., 1981, Report on the Silent Valley Study, Ecology Research Circle, Kumaun University, Nainital, 1981, 86.

Singh M. P., Singh B. S. \& Dey, S.D., 2002, Plant Biodiversity and Taxonomy, Daya Publishing House, New Delhi.

Shruthakeerthiraja. \& Krishnakumar G., 2012, Phytosociological studies on a low altitude forest of the Western Ghats region - India, Indian Journal of Science 1(1), 64-70.

Sukumar R., Dattaraja H. S., Suresh H. S., Radhakrishnan J. V., Vasudeva R., Nirmala S. \& Joshi N. V., 1992, Long-term monitoring of vegetation in a tropical deciduous forest in Mudumalai, southern India, Current Science 62: 608-616.

Vasudeva Rao M. K., 2004, The importance of botanical nomenclature and synonymy in taxonomy and biodiversity, Current Science 87 (5): 602-606.

Verma M., 2001, Economic valuation of forest of Himachal Pradesh, Himachal Pradesh forest sector review, International Institute for Environment and Development (IIED), London: 7.31-7.38. 